\title{
Accountability and the framing power of visual technologies: how do visualized reconstructions of incidents influence public and political accountability discussions?
}

\author{
Victor Bekkers \& Rebecca Moody
}

\section{Introduction}

Traditionally, images have played an important role in politics and policymaking, mostly in relation to propaganda and public communication. However, contemporary society is inundated with visual material due to the increasing ubiquity of media and visual technologies that facilitate the production, distribution, and consumption of images. As such, a visual culture has emerged (Mirzoeff, 1999). However, these visual technologies and the visual events that are created, are not neutral (Sturken \& Cartwright, 2001). The production and distribution of visual material can be seen as a powerful resource that actors may use to frame political issues. For instance, when riots occur, visual material may be used in a reconstruction to suggest answers to the question: what has really happened and who is to blame for what? In doing so visual material might influence the shaping and outcomes of 'blame games' (Hood, 2011). The aim of these reconstructions is to present evidence, so that public investigators, politicians and the general public can understand what has happened in order to address the question who is responsible for what?

In this article, we want to describe, analyze, and explain how visual technologies influence the content and shaping of political and public accountability discussions that emerge in relation to incidents that have caused public upheaval. Several reasons can be given that justify this research question. First, up till now no systematic attention has not been paid to the creation and use of digitized visual events in accountability processes, although there is large body of literature that addresses public accountability (Bovens, 2005). Secondly, typical for blame games is that the involved actors push forward different stories or frames that account for what has happened (Stone,1989). Visual reconstructions play an interesting role in these blame games, because they also tell a story, given the diagnostic claim that is put forward by the makers. They often argue that the visual material used represents 'the truth' about what has happened. However, this is a questionable position. Two reasons can be given. First, accountability questions always touch upon the interests and positions of the involved actors which provokes strategic framing. Secondly, the claim that visual material like photos and videos represent 'forensic evidence', or present some kind of 'photographic truth', is a disputed one, because this visual material is just a specific interpretation of reality which presuppose selection (Mnookin, 1998). Behind a visual reconstruction lie all kinds of assumptions and decisions: what is defined as being relevant and what is not? Who decided to include or exclude specific elements, given the story that is told? Moreover, it is also important to understand the digital nature of these reconstructions which creates all kinds of possibilities for (subtle) manipulation.

In order to answer our research question, we address in section 2 some relevant features of visual technologies that actors may use to frame political issues. Moreover we discuss the role that especially photographic images play in this framing pro cess, due to much disputed belief that pictures tell the truth. In Section 3, we discuss the notion of public and political accountability and the role of visual reconstructions. In Section 4, our research strategy will be described which helps us to describe and analyze two Dutch instances where visual technologies have played an 
important role in trying to answer two questions: what happened; and who was to blame for what? The actual description and analysis of the two cases will be take place in Sections 5, and these are then compared in Section 6. In section seven same conclusion are drawn and some reflections are made.

\section{Visual culture and visual technologies}

Nowadays, human experiences have become more visual and visualized than ever before. This is evidenced in the increasing popularity of social network sites such as YouTube as well as the popularity of taking and exchanging pictures with mobile devices (Mitchell, 1994). However, the emergence of this visual culture does not only depend on the technology. It is rooted in a tendency to picture and visualize human experiences in a more essential way: this is compulsory in the sense that pictures create and contest meanings, while at the same time they relate to, and co-evolve with, other meanings in the public domain. Mirzoeff (1999:3) views a 'visual culture as being concerned with visual events in which information, meaning or pleasure is sought by the consumer in an interface with visual technologies'. Visual technologies are defined as 'any form of apparatus designed to be looked at or to enhance natural vision, from the oil painting to the internet' (Mirzoeff, 1993:3). That images have become increasingly important reflects this growing visual culture (Mitchell, 1994). An indication is the emergence of a complete industry and infrastructure to produce and distribute pictures. This does not imply that text and the printed media have lost significance, but there is clearly an increased use of pictures. Further, their persuasiveness increases if they are combined with verbal or written text, or even with sounds (Marcum, 2002). This visual culture is in essence very fragmented and disrupted, which reflects a dynamic and even fluid culture (Mitchell, 1994; 2005; Castells, 1996; Bauman, 2000). It amounts to an endless, often real time and thus changing, stream of divergent and convergent multiple images with which people are confronted. These images all compete to gain attention (Sturken \& Cartwirght, 2001). Images succeed or fail to the extent that we can interpret them successfully in non-structured and predetermined contexts. Images are inherently open to different interpretations (Mirzoeff, 1999; Mitchell, 2005). Moreover, these images do not portray reality as such. They do not represent the 'truth'.

This truth claim is especially questionable if we take into account the meaning that especially photographic images play in creating 'truth', especially in politics and in court (Mnookin, 1998). The assumption behind this claim is that photographic images can be seen as the outcome of registration and identification process in which a photography is seen as inherently realistic medium (Meskin \& Cohen, 2008; Porter \& Kennedy, 2012). The technologies used are seen as objective and neutral tools, thereby emphasizing the mechanistic process that are used to make this picture or video. The idea is also that the image is an exact copy of reality, which stimulate a way of analogic reasoning: the photo that is presented is an analogy of reality (Mnookin, 1998). Mitchell (1992:24) talks about "an implicit truth claim": a photography "seem to say of what is that is"? This claim is disputed in several ways. Photos, but also images in general, can be seen as a specific interpretation of reality, because all kinds of decisions and assumptions lay behind the specific creation of an image in terms of what camera angle is chosen: what will be made visible and how will it be made visible, what element of the context are in and excluded, what is been accentuated in terms of light, or in terms of lens to be used etc. (Sontag, 1977; Gunning, 2004; Sturken \& Cartwright, 2001)? In doing so, the producers of images try to influence the meaning that possible viewers may attach to it. But also the viewer has his own interpretation of the 'truth' that is being presented. When looking at a picture, he interprets the portrayed version of reality from his own perspective, taken own experiences, his own values, his own interest, his own personal history into account (Sturken \& Cartwright,2001; Crary, 1992). Moreover, a viewer does not take into account the specific context which was relevant for the producer of the 
picture, because he is not always aware of this context, or just not want to acknowledge it. A photo can provide some information about, for instance, a location, but not all information that is relevant to understand this location is present on the photo (Porter \& Kennedy, 2012). Hence, it is important to acknowledge the subjective and contextual nature of images in terms of viewing and producing (Sturken \& Cartwright, 2001; Crary, 1992).

Images play an important role in politics due to the fact that politics has become mediated by citizens who experience politics through the way it is visualized in the traditional media (e.g. newspapers, television news) and the new media (e.g. blogs) (Bennett \& Entman, 2005). The media have increasingly become the platform for politicians to gain political and public support or to discuss political issues such as accountability. This is why the penetration of visual technologies in our society should not be studied as a separate phenomenon: it is an integral part of, and embedded in, broader societal, economic, social, and cultural developments and practices (Mitchell, 1994; Castells, 1998; Bauman, 2000). One such practice is the process of being politically accountable. We will regard visual technologies as the technology to create and distribute a visual event. The scope of these technologies is very large and can refer to photocameras, or software to montage images together to the internet and its possibilities to distribute images such as YouTube as well as cinemas.

In order to understand the power that visual technologies represent, we have to consider certain features of the visual technologies that are used to produce images and so support the process of visualization. We will find that the functions as listed below depend on the technology used to create and distribute the visualization. Therefore technology in itself is partly determinant for whether and to which degree the functions of visuality can be found.

First, the classical function of visualization is registration. Through pictures, people can register or record people, movements, or developments in terms of freezing them in time and place (Mirzoeff, 1999). This generates 'forensic evidence' (Hartely, 1992:35). Since these occurrences are today digitally recorded, they can more easily be edited, duplicated, made accessible, and distributed and exchanged.

Secondly, visualization can make complicated things more transparent in terms of comprehension since one picture often says more than a thousand words (Hartley, 1992; Moody, 2010). Three types of transparency can be distinguished (Snellen, 1994). First, there is informational transparency, reflecting the fact that digitized activities generate information about the way and the conditions under which they are deployed, for instance by making use of user graphics. Second, there is analytical transparency: comprehension can be improved if policymakers are able to use different perspectives on a subject by combining various relevant data. For instance, multiple CCTV cameras located in a single shop will generate images from different angles when registering a robbery. Third, visualization can consequently also increase transparency because it can not only integrate different data but also different perspectives in one 'whole' or sequence of images. In so doing, a somewhat holistic view can be gained. For instance, in the development of visualized scenarios, relevant data, sourced from different databases, can be presented and visualized in an integrated way, making things easier to understand. This is called integrative transparency and a good example is a simulation to show the effects of a river flooding.

Thirdly, visualization facilitates communication. Although 'a picture is worth a thousand words', people will often form different interpretations, and this is often an incentive to communicate more fully in order to create a shared understanding, to develop 'a common grammar' (Weick, 1969). This is the essence of communication. Moreover, images frequently stimulate emotions, they are often used to convince and persuade people, and this may also trigger communication and other forms of interaction (Baumgarten et al, 2006; Fisman, 2003). This helps to facilitate individual and collective learning process about what has happened, or about how effective specific policy measures and instruments actually are, or might be. 
However, these features are not a given, not strictly instrumental, neutral or objective. They are in essence socially and politically constructed features (Homburg \& Bekkers, 2007). Two reasons can be given. First, visualization (and the transparency, communication, and registration functions behind it) have a political meaning because it supports framing process (Kling, 1986; Bijker et al., 1987; Orlikowski, 1992; 2000). In this framing process, social reality is constructed in such a way that it makes political sense, thereby including or excluding certain elements (Stone, 1989; Hajer \& Law, 2006). In essence, this is a political process in which specific stakeholders try to structure reality in such a way that it serves their purposes. Moreover, the use of visual technologies and the production of visual material tends to evolve alongside specific other technological, socio-cultural, political, economic, and also managerial and administrative developments and practices that are seen as relevant (Sturken \& Cartwright, 2001). For instance the use of visual material produced by CCTV cameras can be understood in relation to a sociopolitical development in which the fight against crime in many European cities is high on the political agenda. Secondly, these visual technologies and their features also represent a resource that the involved stakeholders may use to influence this framing process. These features are flexible so that they can serve specific interests and views. For instance, what is the degree of visual registration that takes place in order to produce specific images and why is this degree being strived for? How is the registration been programmed and why has it been programmed as it has? What is the type and degree of transparency that is been achieved? What images are connected with each other and why? (Bekkers \& Homburg, 2007). The political significance of visual technologies, as an exploitable powerful resource, shows that it is important to question whether and how specific stakeholders have access to these technologies, how are they able to exploit these technologies (e.g. knowledge and investments that are needed) and how these technologies are used to support strategies that are deployed to safeguard specific interests, positions and views (Kraemer \& King, 1986; 2006).

Given the fact that images play an important role in politics, we also have to address the issue, how we are going to study these images (Barnhurst et al., 2004). In this paper, we do not view images as having a predetermined meaning, nor will we consider images in the way that linguists look at text. That is, we will not concentrate on the internal structure within the image's design to discover a grammar, syntax, or logic that leads to a specific meaning. Essentially, we will regard images from a pragmatic perspective in which the visual is viewed as a 'social practice' (Barnhurst et al., 2004:629-630; Sturken \& Cartwright, 2001:31, Mitchell, 1994). This implies that the meaning of a visual event is based on the interaction between various actors who bring in different features and contexts, and thus interpretations. It will be interesting to see is if these actors can create a shared understanding of what the image is telling. As such, visual practices include the process and the qualities that emerge in the production of images as well as the qualities of sensemaking that occur during their reception.

\section{Framing accountability}

Accountability has been defined as a social relationship in which an actor feels an obligation to explain and justify his or her conduct to some significant other (Bovens, 2005:184). This explanation and justification process can refer to rather routine like issues, like the periodical evaluation of the results of a policy program. What were relevant implementation risks and how were they managed? However, it can also be linked to non-routine-like issues. These issues refer to incidents that have occurred and that have caused political risks that have affected the reputation and the legitimacy of government (Heath \& Palenchar, 2009; Hood, 2011). In doing so they have the potential to change the political agenda in terms of what issues are politically relevant and have to be discussed. Not only the incident itself but also accountability questions 
that are raised can be therefore be seen as a focusing event (Birkland, 1998; Sulitzeanu-Kena, 2006).

Six elements are seen as important in an accountability process (Day \& Klein, 1987; Meijer, 2001). First, there is a triggering or focusing event that starts the accountability process. Second, there is an actor who is the 'accounter' (an individual or agency) who is accountable or held accountable for what has happened (Bovens, 2005). Third, there is a situation or an action for which the actor is being held accountable. A vital question is whether there is a causal relationship between the occurrence of a situation and the actions or negligence of specific individuals or an agency that contributed to this situation. This question generates a desire to unravel a hidden truth. Fourth, there is an accountability forum to which a person or agency is held accountable. For instance, when talking about political accountability, these are elected officials who are part of a legislative controlling body, such as a parliament or municipality council. Political accountability is about those with delegated authority being answerable for their actions (Day \& Klein, 1987). In the case of public accountability, the relevant forum is the general public - the citizens of a country constituting a political community (Stone, 2002). Fifth, there are criteria to be applied to assess whether the accounter is truly accountable. Very often these depend on the forum. When dealing with political and public accountability, and given the possible causal relationship between a situation and the actions that have been taken, norms are important in determining who is accountable for what, and to what extent. Moreover, it is important to pose the question that given these norms, and given the actions that have been taken, harm could have been avoided (Sulitzeanu-Kenan \& Hood, 2005). A number of relevant political, legal, professional, and ethical norms, as well as the personal qualities of the involved public officials, need therefore to be considered (Schedler, 1999; Bovens, 2005). This is often difficult since there is no clear relationship between the actions of a single individual or agency and the occurrence of a specific event due to the fact that many different individuals or agencies have been involved, who are all only responsible for one aspect and not for the whole (Bovens, 2005). The final element refers to sanctions: sometimes sanctions may be imposed on an individual or agency, such as the dismissal of the responsible minister.

Our primary aim is to understand the role visual technologies play in the information and discussion phase of the accountability process, and how they are used to frame specific accountability issues that are related to incidents that have caused political and public upheaval (Bovens, 2005). Framing can be seen as sense making because it links facts, values, actions, and interpretations in such a way that ambiguity is reduced and a specific meaning created (Stone, 1989; Hajer \& Law, 2006). It is a scheme of interpretation. To understand this framing power we need to know how the various features of these technologies are used to reconstruct the occurrences being investigated sot that they make sense. Reconstructions are primarily focused on trying to understand the causal relationship between the occurrence of a situation and the possible causes; and between the actions that were taken in dealing with this situation and their outcomes in terms of being able to bring a specific situation under control (achieve finality). These causal and final relationships can be viewed in terms of framing: making sense of what has occurred through a specific ordering of elements. Snow et al. (1986) distinguish three types of frames. Diagnostic framing refers to the identification of a problem and the allocation of blame or causality. Prognostic framing refers to the proposal of solutions together with the necessary strategies, tactics, and targets to implement them. Finally, motivational framing refers to the process of convincing followers in order to entice them to act.

A reconstruction based on the collection and combination of relevant information in order to reenact, by looking back, a chain of events, is not neutral. This is particularly evident when we consider that many such events, especially if they relate to a disaster, have a rather chaotic nature (Stone, 1989; Heath \& Palenchar, 2009). A visual reconstruction can be seen as the telling of a 
story in which specific elements are included and visualized, while other elements are excluded. Moreover, given that some information is absent, incomplete, or ambiguous, gaps have to be filled: so what story is actually being told? Three story forms, in which framing plays an important role, can be distinguished.

The first one is the so-called forensic visual story that claims to present forensic evidence: the visual presentation of events that allegedly have taken place, which aims to make a hidden or unknown reality accessible and transparent (Hartley, 1992:35). Diagnostic framing dominates in this type of story. Important is that the creators of this type of story claim to present a diagnostic 'truth': the visual material that is presented in the reconstruction is based on an analogy of what has happened (Mnookin, 1998). As such the material that is used, is given the status of a 'silent witness' (Mnookin, 1998:38). As we have argued before, we should be aware that this claim is a false one, given the choices and assumptions that the maker and users of these images had when they produced, selected and edited these images (Sturken \& Cartwright, 2001:17 Crary, 1992; Lister et al., 2003 ). That is why American courts define visual representations only as 'demonstrative evidence', it is just one source of evidence that together with other sources create a specific degree of certainty of what has happened (Mnookin, 1998:35). Visual material is too often been used to support the truths by bringing an artificial level of credibility to unreliable evidence (Mnookin, 1998; Porter \& Kennedy, 2012). Therefore, Mitchell (1992:40-41) argues that the credibility of visual material which is used as being 'forensic evidence' can only be safeguarded, if "the caption can be plausibly reconciled with the facts as we know them and that the claim that is made can be cross-checked against what we know of a situation or a location, how trustworthy or authoritative the originator is and how the image was presented to other people'? Consistency and provenance seem therefore important conditions to be taken into consideration, when presenting visual material as being the 'diagnostic truth'. These remarks become even more important, if the we take into account visual material has become more and more digital, which offers all kinds of possibilities for manipulation and reconfiguration (Mitchell, 1992). That is why Postman (1993; see also Meskin \& Cohen, 2008) argues that we should be reluctant to think that the truth is in what we see, because visual material, especially photographic material tends to suppress logical thinking and contextual knowledge.

The second type is the 'persuasive visual story'. Here, visual events are created in order to appeal to our emotions, because the creators want to convince people. Visual events are used to dramatize, thereby articulating some elements more than others, albeit without telling lies. In so doing, the creators want to exercise control over how people think or act as they become inspired by the images presented (Sturken \& Cartwright, 2001). Motivational framing is the dominant form in this story.

The third type is the imagined visual story where an imaginary view of reality is presented through the creation of visual events (Moody, 2010). The most powerful form is the use of virtual reality and other forms of simulation technologies to portray possible future scenarios that are based on the manipulation of specific parameters based on 'what if...' reasoning. In these stories, prognostic framing dominates, and specific frames are advanced in order to create an understanding of what has happened.

Even though in literature it is shown that these three types of stories are separate stories, in our analysis we will demonstrate that this distinction is empirically difficult to hold. Additionally it must be noted that these three types of stories refer to the story someone aims to tell, not what the story actually is. In other words, if one wants to tell a forensic story it does not mean that his images are unbiased or forensic in itself, he will only portray these images as such.

\section{Research strategy}


In order to describe, analyze, and explain how visual technologies can be used to influence the reconstruction of events in order to shape public and political accountability discussions, we formulate a number of possible expectations, based on the theoretical exploration in the previous sections. We will not analyze the image itself in a semiotic manner, but we will look at the influence that images have on the shaping of accountability discussions, thereby looking at the meanings that relevant stakeholders attach to these images.

The first set of expectations reflects the ways in which the visual reconstruction of an event is influenced by the strategic framing of those actors that are involved in the visual construction. We expect such actors try to tell a story in a visual reconstruction. This story can be classified as a forensic, a persuasive, or an imaginative one. We assume that visual material will be used in the reconstruction to support a story line in which a specific kind of ' truth' will be presented, thereby making use of the visual material that is being gathered or produced. We also expect frames to be advanced as possible explanations in order to create an understanding of what caused the situation to occur as well as of the outcomes of the actions taken to deal with the situation. Moreover, we suppose that framing will be used to convince people, especially when a persuasive or imaginary story is to be told. Further, we expect a forensic story to be the dominant choice when the emphasis is on the production of frames to make sense of what has happened. We believe that the stakeholders involved in telling a specific story will use visual technologies as a powerful resource. Hence, the access they have to specific visual technologies, that produce the images, also influences the story being told.

Secondly, we expect a relationship between the story being told in the reconstruction and the use of specific features of visual technologies by the actors involved. We assume that registration and transparency features are more important when actors want to tell a forensic story, thereby appealing to the idea of 'photographic truth'. When actors want to tell a persuasive and imaginative story, transparency and communicative features will be the most important.

The third set of expectations refers to the relationship between the content of the accountability discussions in the political and public realms and the dominant story being told in the reconstruction. If the dominant story being told in the visual reconstruction influences the public debate, we would expect to see a match between the dominant story being portrayed in the reconstruction and the content of the accountability discussions in the media. Given the dominant role that the media play in society, and their influence in setting the public agenda, we would argue that an analysis of the media coverage would provide a relatively good indicator of the discussion in the public realm (Walgrave \& Van Aelst, 2006).

Having established these potential relationships, the next step is to see whether these expectations are confirmed in empirical research. Here, we will use a comparative case study strategy (Yin, 2003). A case study has the advantage that is recognizes the complex nature of social phenomena in a coherent and integrated way, giving attention to the meaning that actors attach to the complex interplay between different specific factors and various actors and their views and interests. This can create an in-depth understanding of social phenomena, which is especially important when considering framing processes since these processes depend on the meanings that relevant actors want to attach to a reconstruction in order to influence the accountability discussion. Moreover, these discussions have a highly qualitative nature in dealing with the question: who is responsible for what? (Yin, 2003).

In order to research the influence of visual reconstructions the first question that comes to mind is how to handle the causality, how to prove that there is a causal relation between the reconstruction and policy. Since in none of the cases it is possible to recreate the same 
occurrence and see what would happen in the case no visual reconstruction had been made we need a different approach. We will argue that the relationship between the visualization and the policy process is causal on the basis of plausibility. This plausibility can be argued by three points. Firstly we will show that the content of the discourse in politics and media changed after the broadcasting of the reconstruction towards the same frame as held by the reconstruction. Secondly we will demonstrate that respondents in interviews but also in newspapers and online forums claim that they have undertaken actions or changed their opinion because of the power of the images in reconstructions. Thirdly the plausibility will be argued by looking at events chronologically. This will demonstrate that actions are taken on the basis of previous events, in our cases the reconstruction.

In order to study the public accountability discussion we will use three types of empirical data. Firstly we will analyze two national papers and the news coverage by the eight o'clock television news. The two national papers which will be analyzed are the progressive left-leaning Volkskrant and the more conservative and populist Algemeen Dagblad (AD). Moreover we also look at the coverage in the NOS journal (the eight o'clock news on television) which is considered by the public as the most trustworthy source of information in comparison to the other news magazines of RTL4 and 5 and SBS6. Moreover the NOS journal of eight o'clock has most viewers and is considered the most reliable television news broadcast ${ }^{1}$.

Secondly, we analyze the written proceedings of the involved political bodies, like Parliament or municipality councils. In these proceedings we will look at differences in frames before and after the broadcasting of the reconstruction. Also we assume that if the dominant story told in the visual reconstruction influences the public and political debate, we would expect to see a match between the dominant story being portrayed in the reconstruction and the content of the accountability discussions in the media and the involved political bodies. In doing so we try to make plausible that the story that is told in the reconstruction is adopted in the public and political debate. Additionally we research whether in the reporting of the involved political bodies explicitly is referred to the framing power of the reconstruction itself and the visual material that is used.

Finally the proceedings of the interviews that we have conducted and that have been analyzed are used. We conducted semi-structured in-depth interviews with thirteen relevant stakeholders, that have an active role in the case studies, because they were involvement as senior civil officer, investigator, and producer of the reconstruction. Given their close involvement they were able to give us relevant information about the framing process that took place during the making and editing of the reconstruction. What we view as striking fragments presented in these interviews are included in the case descriptions and placed within "double quotation marks".

The combination of these three data sources and techniques also enhances the reliability of our findings, because it is based on a process known as triangulation (Yin, 2003). First, we observed and analyzed the way in which these issues and their reconstruction were presented on the eight o'clock television news. Secondly, we analyzed the content of relevant policy documents, parliamentary and municipality council protocols, as well as of relevant articles in the two selected newspapers. Thirdly, we conducted semi-structured in-depth interviews with relevant stakeholders in order to reconstruct their motives, interests views and actions.

The selection of cases for our study, in which two cases are compared, is based on the following criteria that both cases have in common. The cases should have caused significant political and public upheaval. Questions should have been raised regarding the accountability for these events occurring, and the issues debated in a political and public forum. Moreover, in both cases a visual

\footnotetext{
1 http://radio.nl/4331/nos-journaal-meest-betrouwbare-nieuwsbron-van-nederland
} 
reconstruction should have been made. Given that our case study design seeks similar cases, some generalization is possible. However, we are not aiming at a statistical generalization but only at analytical generalization (Yin, 2003) where a convincing and coherent line of reasoning is presented based on plausible research outcomes. The first case relates to a fire in a Dutch penitentiary at Schiphol, where a number of immigrants awaiting deportation died in the fire. The second case addresses 'riots' during a music event - Sunset Grooves - on the beach near Hoek van Holland.

We do recognize that both cases are located within a specific institutional and socio-political context which may limit generalization in other context. However we do want to argue that analytical generalization in terms of frame changes because of visual events remains possible since the change itself does not depend on the context. Only the content of the change and possibly the gravity of the change might be different. For example, in countries with different institutional settings or a different media culture (for example large sensational- and yellow press) the content and the gravity of the frame change might differ.

In order to systematically describe, analyze, and then compare these two cases, the following analytical model is used.

[table 1]

\section{Table 1: Analytical Model}

The table demonstrates that on the basis of our expectations derived from theoretical notions it is first important to look at the event itself. The next step is to see why and how a reconstruction was created. The creator, as explained, would have to choose between different technologies in order to create the reconstruction and these different technologies also are determinant for the function of the visual event itself. Additional to this choice, the creator would have to establish which kind of story he would like to tell, which images to use in order to tell this story and which technology suited him best in telling the story. We can then view the reconstruction and not only find what the dominant frame of the creator was, but also find whether and how this frame was adopted by other media, such as newspapers, broadcasting media and the actors involved in the cases.

\section{Empirical study}

Based on the relationships that we have discerned in the analytical model, we will describe, analyze, and compare two selected cases.

\subsection{Fire at a detention center}

\section{The call for accountability}

On October $27^{\text {th }} 2005$, a fire broke out in the detention center in the Dutch city of Schiphol. The center was built to house asylum seekers that had not been granted a residence permit by the Dutch authorities and were to be deported. In the fire, 11 people died and 15 people, including some guards, were injured. Immediately after the fire, questions were raised in the media regarding the safety offered to these people, including in relation to the problems that the fire brigade encountered when trying to enter the premises. In the discussion, it was also emphasized 
that these people were not really prisoners, there because of criminal activity. They were detained to prevent them from going into hiding. The government asked the 'Dutch Safety Board' (Onderzoeksraad), which had recently been established in February 2005, to examine the situation. This Board is an independent organization whose main purpose it to investigate such incidents. The actors most involved in the enquiry were: two agencies falling under the jurisdiction of the Minister of Justice - the Immigrant and Naturalization Agency and the Penitentiary Agency; one agency that deals with the construction and maintenance of government buildings that falls under the jurisdiction of the Minister of Urban and Rural Planning, Housing, Environmental Affairs; the municipality of Amstelveen in which the building was located and that was responsible for the issuance and control of fire safety permits; and the emergency services (fire brigade, ambulance) within the Schiphol region.

\section{Visual technology and reconstruction}

Given that the Board was asked to independently investigate the incident, they had freedom in how they reported on the incident. In addition to their report, the Board opted to make a fifteenminute long reconstruction based on film images that showed a building burning down in combination with animation sequences ${ }^{2}$. Both the report and the reconstruction were presented on September $21^{\text {st }} 2006$. The animations were used to show how the fire spread, and how the emergency services arrived and then proceeded. These animations tried to imagine what had happened in order to gain a better understanding of the chain of events. The film images were a compilation of images filmed immediately after the fire - showing perceived forensic evidence such as the remains of what were once cells, a blackened phone dangling in the air, and a burnt bed standing alone in a burnt-out cell. Moreover, a voice and music in a menacing tone accompanied the images. When the reconstruction starts, a voiceover introduces the disaster using the following text: "A cell block at Schiphol-East, distorted steel, blackened walls and burnt cells. Silent witnesses of a disaster, in which 11 people were killed without having a chance, locked in their cells, suffocated by the smoke. Could this disastrous fire that started in one cell have been prevented? Did these people have a chance to live? Did the emergency services work well? Did the building meet all the requirements? Did the responsible officials properly use the recommendations and reports that were available and that discussed the fire safety of the building?...”.

\section{Framing and reconstruction}

The Board was aiming to create a documentary-like reconstruction through which they could try and understand what had happened, and also to determine whether the actions taken in dealing with the disaster had been appropriate. The producer of the reconstruction and the Board both claimed that they not only wanted to show what happened but also to give the victims a voice. The Board, introducing itself in the reconstruction as "a vital agency to protect the interests of citizens", wanted to frame the incident in terms of "a failing government unable to care properly for those it was responsible for". This was the dominant line in the story told, and it received a lot of critique. The makers were trying to persuade the audience that these people had been "trapped like rats". Several respondents from the accused organizations felt that the reconstruction, however correct in its facts which could also be cross checked by reading the written report of the Board, portrayed the incident in a very emotional way, with the zooming in on personal belongings of the residents and highlighting the situation of the people. They felt that the film was not aimed at reconstructing what happened but was trying to make a point - to take a stand. The critics argued that the reconstruction was made to give the newly established

\footnotetext{
${ }^{2}$ www.youtube.com/watch?v $=\mathrm{c} 4 \mathrm{vfV} c x 9 \mathrm{YmM}$
} 
Dutch Safety Board - certainly because its predecessor had limited tasks which only referred to investigating traffic incidents, while this incident was the first outside this domain - some standing, and that they used the reconstruction to frame the political opinion in a specific way: "that the prisoners were treated badly" and "that the government had been negligent". The reconstruction was considered by most of the involved actors as non-objective, going beyond the hard facts. The Dutch Safety Board was accused of acting as a public prosecutor rather than as an independent research institute. The reconstruction was defined as being 'dramatized', 'an overreaction', and 'unfair', thereby suggesting a motivational framing by the Board. The Dutch Safety Board responded to this criticism by stating that it was their job to show the Dutch public what had happened in terms of presenting the facts. They also wanted to show the personal and emotional impact of the fire. They claimed that "the prisoners could not speak for themselves since they had died, and that their next of kin could not speak to the Dutch public since all the prisoners were foreigners". The Dutch Safety Board feared that the victims would stay 'invisible' because of their status as imprisoned asylum seekers. According to several respondents, an important driver for the Board's political claim was the need to legitimize its own independent position because it was new. According to the critique, some elements were also left out of the story being told. The heroic behavior of the guards, many also injured in helping the prisoners, was neither shown nor mentioned. Although the visual reconstruction had only been intended to support the written findings of the Board, the visual reconstruction became seen as "the" report, because so much of the attention was drawn to it. Some respondents referred to it as "leading a life of its own".

\section{Framing and accountability}

The Board's research pointed to an overwhelming set of mistakes that had been made, including various fire, safety and building norms that were not taken into account. Since compliance with these norms may have prevented the death of many people, the question became who was responsible? Shortly after the presentation of the report and the visual reconstruction, political turmoil emerged. Firstly, the minister responsible for the safety of government buildings, including prisons (Mrs Dekker) stepped down. Due to the rapidly emerging political and public pressure, partly linked to Mrs Dekker's emotional outburst when watching the reconstruction and taking into account the conclusions of the Board, the Minister of Justice (Mr Donner), who was responsible for immigration issues, also resigned. In interviews it was stressed that the visual power of the reconstruction was so overwhelming that a snowball effect was set in motion. Respondents claim that it was the visual reconstruction causing the public and political turmoil, not the report behind it. A respondent claimed: "the film was the source of energy of the debate, not the report, and this led to turmoil. One can try to get to the core of the events, but you can't, not with such a film." Media coverage played an important role in building this pressure, thereby setting the tone in the public accountability discussion. The Volkskrant reported: "Van Vollenhoven (chairman of the board) does not hide his anger. Besides his fearless presentation, he astonishes everybody with a reconstruction of the disaster. With the help of animation, existing video pictures and even music, the deaths, the mistakes, and the failures transcended the sober tone of the report, and for the general public the drama came alive. For anybody watching the images of the fire brigade stuck in one of the entrance corridors of the prison, it was obvious that you did not need to finish film academy to understand what the impact would be on the maneuvers in The Hague..."3. In their reporting, the Volkskrant adopted not only the diagnostic frame of the Safety Board but also its motivational frame. One day later the paper added: "It is especially the video of the fire that is very impressive. No arguments can cope with these

\footnotetext{
${ }^{3}$ http://www.volkskrant.nl/vk/nl/2686/Binnenland/article/detail/781644/2006/09/22/Van-Vollenhovenverscherpte-oordeel.dhtml
} 
pictures. Donner at that moment writes his farewell speech at the ministry"4. The more conservative AD primarily focused on the mistakes made. In a small article they also refer to "a flashy DVD" with animations and film material that shows how the fire occurred. The paper interviewed the maker of the DVD, who referred to its importance: "Such an audiovisual production helps to make things comprehensible"; while a professor in mass psychology who was also interviewed referred to the "persuasiveness of the film in showing what had happened" . In so doing, the ability of visual technology to make this event transparent is being stressed, while at the same time questions are being raised regarding the motivational framing of the Board. Also the Dutch eight o'clock TV news (NOS Journaal) stressed the importance of the visual reconstruction in illustrating the number of mistakes that had occurred: " $\mathrm{A}$ sinking feeling took possession of the public (who was present at the presentation of the report) when the film showed how little chance the victims had". Here, NOS was adopting the diagnostic frame set by the Board. However, the eight o'clock news also highlighted strong and weak points of the presentation. "The film has the advantage that it offers an accessible account. However, in order to get attention, a thrilling video was made: music, sound effects, and rhetoric". The news continues by noting "that one could gain the impression that the Board has been guided by their emotions". Hence, they were questioning whether the conclusions of the Board were based on facts or on emotions, but the anchorman carried on: "However, the facts are so convincing. What the video has achieved is that the conclusions have hit faster and harder". As such, the diagnostic frame of the board was so powerful that the possible negative effects of its motivational framing were not seen as unjust.

Before the report was presented, Parliament discussed this issue several times with the two ministers responsible. In their first meetings, the emphasis was on the possible shortcomings of the building's fire safety and the appropriateness of the help that was provided by the rescue services. Later, the emphasis shifted and questions were raised regarding the way in which survivors were threatened and the lack of care provided. Then, the report and reconstruction were presented. The Members of Parliament then regretted that, due to the sudden resignation of the two ministers, no proper debate was possible about the accountability issue, although they did understand why the ministers had resigned given the mistakes that were made. The resignation of the two ministers took the sting out of the debate. However, the issue was debated with their successors. This debate focused primarily on two questions: what caused the fire, and could it have been prevented. In dealing with these two questions, the reconstruction played an important role, according to respondents a much larger role than the report. Some MPs emphasized the accusatory nature of the sound elements within the film which had created "too much emotion" The new Minister of Housing, Pieter Winsemius, also referred to the piano music and the cheerful voiceover at the beginning of the film, which he considered as "an insult to the people

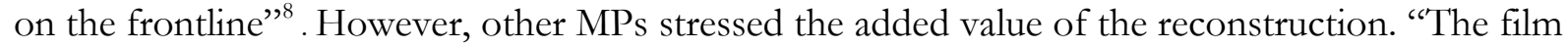
shows $(. .$.$) extremely well what has happened. Also for the general public it has become clear$ what caused the fire and how this drama could take place". The new minister added: "You can

\footnotetext{
${ }^{4}$ http://www.volkskrant.nl/vk/nl/2686/Binnenland/article/detail/781642/2006/09/22/Donner-besefte-snel-ditred-ik-niet.dhtml

${ }^{5}$ http://www.ad.nl/ad/nl/1012/Binnenland/article/detail/2359553/2006/09/22/Flitsende-dvd-toont-hoe-brandverliep.dhtml

${ }^{6}$ http:// nos.nl/koningshuis/video/22332-pieter-van-vollenhoven-presenteert-rapport-over-brand-schipholoost2006.html 21/09/06

${ }^{7}$ https://zoek.officielebekendmakingen.nl/h-tk-20062007-1117-1144.html? 24/10/06

8 https://zoek.officielebekendmakingen.nl/h-tk-20062007-1190-1233.html? d.d.25/10/06

${ }^{9}$ https://zoek.officielebekendmakingen.nl/h-tk-20062007-1117-1144.html? 24/10/06
} 
say a lot about this film, but is has been extraordinarily instructive. You can actually understand how the fire moved through the shaft" ${ }^{10}$.

Hence, we see that, in the political debate, the reconstruction also played an important role. While it helped in understanding what had happened (in terms of transparency), the persuasive nature of the reconstruction was disputed. In the political debate, this element did not play a significant role whereas it had in the public debate immediately after the report was presented, creating pressure for the ministers' resignations.

\subsection{Sunset Grooves}

\section{The call for accountability}

The 'Sunset Grooves Riots' took place in Hoek van Holland, a town that politically falls under the City of Rotterdam, where on August $22^{\text {nd }} 2009$ a large dance event had been organized on the beach. There were about 30,000 people present, which were more than anticipated. Throughout the festival, some minor violence took place, but the riots only started when a group of visitors recognized two undercover police officers. The public attacked the two officers and other officers who came to help them were also attacked. The police were forced to pull back and retreat through an emergency exit but the rioters broke the fences and followed them, driving them towards the ocean. The police shot in the air but were unable to control the situation; and eventually they shot at the public coming after them. One person died and a number of people were wounded. Several accountability issues were raised. Most attention focused on the quality of the festival's organization, especially in terms of security and emergency measures taken, given the large number of people attending. Another question raised concerned the efficacy of the police organization. It was suggested that the police underestimated the nature of the festival and the number of people expected, and questions were also raised regarding the effectiveness of the chain of command during the riots and why there was no riot police available as backup. Also it was suggested that, some days before the festival, the police had received intelligence that potential rioters would attend the festival in order create a disturbance. Attention was also focused on the abuse of alcohol and drugs by the involved rioters. As in the previous case, investigations were ordered. In particular, the actions of the Rotterdam-Rijnmond police force and the mayor of the municipality of Rotterdam, who is responsible for public safety, became subjects of the investigation. The Institute for Safety, Security and Crisis Management (COT) investigated the policy measures: the quality of the preparation, the risk analysis, and the briefing. The National Police Internal Investigations Department (Rijksrecherche) investigated the actions of the police officers who had used their guns. These officers were formally suspects, but it was ruled that they acted in self-defense. A special police team investigated the public present at the time of the riots and identified forty suspected of public disturbance, violence, and threatening the police.

\section{Visual technologies and reconstruction}

Soon after the incident all kinds of images were put on YouTube, thereby showing that a lot of visual material was available. Using this information, the Rijksrecherche made a reconstruction, partly to support the work of the COT. This reconstruction consisted of a number of different types of images. First there were animations of the event site showing who (the police and rioters) were where and when. Secondly, images shot by a Dutch television company which had been broadcasting the event were used. Thirdly images were used which were filmed by people

${ }^{10}$ https:// zoek.officielebekendmakingen.nl/h-tk-20062007-1190-1233.html? d.d.25/10/06 
using their mobile telephones. Some of these images had been uploaded real-time on to YouTube, others were provided later to the police. These images were later used to identify suspects. Finally images from 'bodycams' (a camera device connected to the collar of a police officer's uniform) were used. The camera sees what the officer sees, and this was the first time such images were used for this type of analysis. All these thousands of pictures and short films recorded individualistic, real, but scattered accounts of what was happening. The Rijksrecherche was able to cluster these individual images such that a more integrated account was created. Moreover, the quality of the account increased because the Rijksrecherche was able to show the specific course of events from different perspectives, referring to specific sounds that could be heard and also making use of the digital time recording of the cameras and phones used.

\section{Framing and reconstruction}

According to all the respondents, the reconstruction offered a realistic view of what had happened. However, with the 'live' images, emotion could also be seen: panic among the people present, as well as their shouting; and shouting, panic, and despair in the faces of the police officers as they were driven into the sea. The reconstruction showed a very frightening image of a trapped group of police officers. According the COT the images that were used in the reconstruction "have a verifying function, because "witnesses tell a lot but for them the events on the beach were traumatic events. (...) these pictures show you exactly what have happened". At the same the police admitted that the "quality of the pictures that were taken, varied. (...) especially the pictures and videos that were put on YouTube, did not have a very good quality. The pictures of the special hooligan unit which was also present during the riots, did have a better quality: "they have a high resolution and you can use them to zoom in". The quality of the body cam pictures of the police, which were also used, depend on "the features of the surroundings. In the dunes it is very dark, so the view is very limited. If you have much light, then the pictures are fine. Also the sounds to recorded, disappear when shots are fired". Also pictures that showed the killing were not inserted in the reconstruction, while the faces of the involved policy offers were deliberately vague in order to prevent possible reprisals.

On the basis of the images within the reconstruction, many adopted a frame that "there was nothing else the police could have done". Moreover, it seemed clear that the police were confronted with a crowd that was completely out of control. A quote of one of the respondents illustrates the content of the frame that was put forward. "The reconstruction shows how the events did take place (..).. You can see this, also because they are in line with the statements that were made (...) And of course, with these mobile phone recordings, you are living in a glass house. Recordings which are completely context loose, but by linking these recordings you can show the real story...(.).. It was good to see how these images relieved us and how they incriminated the offenders, everybody could see that"

\section{Framing and accountability}

Initially, the public and political discussion regarding the incident focused on possible mistakes by the police. After the presentation of the report and the reconstruction, another frame became more important. If we look at the public discussion, as it was voiced by the media, we see that the Volkskrant's emphasis in its reporting was that the police had no other choice but to shoot. Referring to the reconstruction, ${ }^{11}$ the line was that the police had the right to do so. The pictures and sound fragments that were shown when the report was presented on $12^{\text {th }}$ September 2009 ,

\footnotetext{
11 http://www.volkskrant.nl/vk/nl/2844/Archief/archief/article/detail/373507/2009/12/09/Politieoptredendancefeest-terecht.dhtml
} 
were qualified as "bloodcurdling" and "telling the truth". "Somebody who would dare to argue that the 21 police officers should not have used their guns during the riots, he or she is 'a loud mouth'. The pictures show that the 45 police officers were not able to control a crowd consisting of 200-300 people" 12. A day later, the Volkskrant reported that "the reconstruction strengthens the impression that it was a miracle that only one person died". "How did the police officers get

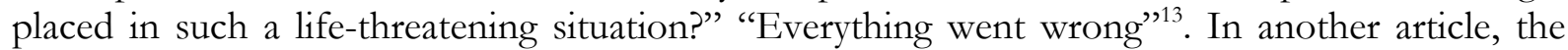
paper referred to the neutrality of the reconstruction, thereby implying that is was an accurate description of what had happened. "Back they go, through the dunes. Warning shots do not help. In 7 seconds, 13 shots are fired, leading to one death. The crowd is still attacking (...)"14. The Volkskrant then considers who is to blame. "The report is devastating for the police commissioner, Ad Meijboom, and his organization. His position is at stake"15.

Prior to the presentation of the report, the eight o'clock TV news had given much attention to the Sunset Grooves riots, showing that too many people were present at the festival, the lack of security measures, as well as the unpreparedness of the police ${ }^{16}$. Also visual material that had been uploaded on to YouTube was being included, showing the chaotic and threatening nature of events on the beach ${ }^{17}$. However, once the reconstruction was presented, the frame of NOS Journaal changed drastically, now using fragments of the visualized reconstruction and adding comments such as "a crowd of hooligans completely out of all control", "police officers with no chance against this overwhelming power, which explains why they took out their pistols", and "officers felt they were trapped like rats, because they were in a minority. They called for the riot police but no help was available. Warning shots did not help"18. Some days later, questions were raised concerning who was to blame. The police commissioner acknowledged in an interview that he was responsible. NOS Journaal commented that his position was at stake ${ }^{19}$.

Hence, we see that, in the public media discussion, a new diagnostic frame was adopted stressing that, given the amount of violence, the police could not have acted differently. This put the original diagnostic frame, in which the organization of the police was discussed, in a new perspective. However, this new frame did not fully suppress the original diagnostic frame which stressed that the police had made mistakes. This explains why, in the public accountability

\footnotetext{
12 http://www.volkskrant.nl/vk/nl/2664/Nieuws/archief/article/detail/373490/2009/12/09/Het-loopt-hier-he-lemaal-uit-de-klauwen.dhtml

13 http:/ /www.volkskrant.nl/vk/nl/2664/Nieuws/archief/article/detail/369459/2009/12/10/Vernietigendoordeel.dhtml

${ }^{14}$ http://www.volkskrant.nl/vk/nl/2664/Nieuws/archief/article/detail/368599/2009/12/10/Het-aantal-

hooligans-groeit-en-groeit.dhtml

${ }^{15} \mathrm{http}: / /$ www.goldies.nl/portal/modules.php?name=News\&file=article\&sid $=525$ Originally in the Volkskrant http://www.ad.nl/ad/nl/1012/Binnenland/article/detail/2059100/2009/12/09/Probleem-rond-strandfeest-nietalleen-schuld-politie.dhtml; http://www.ad.nl/ad/nl/1038/Rotterdam/article/detail/2056657/2009/12/09/Politiejustitie-en-gemeente-faalden-bij-strandfeest-Hoek.dhtml

16 http://nos.nl/video/41588-dode-bij-schietpartij-strandfeest-hoek-van-holland.html 23/08/09; http://nos.nl/video/41600-onderzoek-hoek-van-holland-in-volle-gang.html 23/08/09

17 http://nos.nl/video/41678-henrikwillem-hofs-over-sunset-grooves.html 24/08/09;

http://nos.nl/video/41686-getuigen-alleen-politie-schoot.html 24/08/09;

http://nos.nl/video/41685-verslaggever-lidwien-gevers-in-hoek-van-holland.html, 24/08/09;

http://nos.nl/video/41783-hooligans-extreem-gewelddadig.html 25/08/09

${ }^{18}$ http://nos.nl/video/113762-aboutaleb-tijdens-persconferentie.html 09/12/09; http://nos.nl/video/113754-

overzicht-rellen-strandfeest-hoek-van-holland.html 09/12/09; http://nos.nl/video/113761-reconstructie-rellen-

hoek-van-holland.html 09/12/09; http://nos.nl/video/113789-verslaggever-bink-over-rellen-hoek-van-holland.html 09/12/09; http://nos.nl/video/113787-cot-autoriteiten-faalden-bij-rellen-hoek-van-holland.html 09/12/09;

http://nos.nl/video/114445-cot-alles-ging-fout-bij-rellen-hoek-van-holland.html 09/12/09

${ }^{19}$ http://nos.nl/video/119653-meijboom-wil-onrust-politiekorps-sussen.html 12/12/09
} 
discussion, the position of the police commissioner, as being primarily responsible, remained an issue.

In terms of the influence of the framing on political accountability, we can reflect on two meetings of the Rotterdam municipality council which were dedicated to the riots. Just after the riots, on $3^{\text {rd }}$ September 2009, the council discussed the issue, referring to the first pictures that were to be seen on the internet. ${ }^{20}$ The emphasis by the mayor, taken up by the other council members, was on the role of rioters. "The police were attacked by a bunch of lawless people", "a new generation of criminals who were fuddled with drugs and alcohol, and capable of terrible deeds", also described as "crazy lunatics" and "hyenas". Questions were also asked whether the mayor and the police had taken all the relevant information about possible risks into account when granting a permit for the festival. Thus, in the political discussion, the behavior of the rioters dominated while, in the public media discussion, at least until the reconstruction, this was just one of the aspects under discussion. Following the COT report, another council meeting was organized for the $17^{\text {th }}$ December 2009. Taking into account the visual reconstruction of the riots, the discussion this time focused on the "heroic behavior of the police officers" who "deserve respect". The influence of the pictures was also mentioned several times "I have seen the pictures many times, and each time again they go for my throat", "pictures that make my flesh creep", and "a bunch of hyenas that are out of control" 21 . We can see that the dominant frame from the first council meeting was reproduced in the discussion at this second meeting, although the police were now perceived as not only trapped but also as heroic. However, another frame was emerging: who was responsible for the chain of events, especially given the safety measures which were taken in preparation for the event and the effects on society? It was being argued that the event illustrated the "the general public had lost confidence in the police as being able to restore public safety". The mayor was not being viewed as responsible, in contrast to the police commissioner. Some political parties asked the mayor to take personal measures against the police commissioner. Despite the criticism, the police commissioner was not dismissed. However, some months later, on $8^{\text {th }}$ February 2010, the police commissioner resigned arguing that he was not able to implement the measures that had been imposed on the police in order to improve effectiveness.

\section{Comparative case-study analysis}

In this section, we compare the two cases by analyzing the case study descriptions in terms of our analytical framework. Given our expectations, what are the striking similarities and differences, and how can they be explained? In both cases, we see that incidents gave rise to a set of related accountability issues, and two major questions. What caused the incident, and were the responsible agencies or organizations capable of dealing with this emergency - in terms of their

\footnotetext{
${ }^{20}$ http://www.bds.rotterdam.nl/Bestuurlijke_Informatie:7/Raadsinformatie/Gemeenteraad_2006_2010/2009/Kwar taal_4/Raadsvergadering_van_5_november_2009/Vaststelling_van_de_notulen_van_de_raadsvergadering_van_3_s eptember_2009_en_17_september_2009/Notulen_van_de_raadsvergadering_van_3_september_2009?search=true ${ }^{21} \mathrm{http}$ // www.bds.rotterdam.nl/Bestuurlijke_Informatie:7/Raadsinformatie/Gemeenteraad_2006_2010/2010/Kwar taal_1/Raadsvergadering_van_18_februari_2010/Vaststelling_van_de_notulen_van_de_raadsvergadering_van_a_12 _november_2009_b_3_december_2009_17_december_2009/Notulen_17_december_2009/17_december_2009_oc htend? search $=$ true;

http://www.bds.rotterdam.nl/Bestuurlijke_Informatie:7/Raadsinformatie/Gemeenteraad_2006_2010/2010/Kwarta al_1/Raadsvergadering_van_18_februari_2010/Vaststelling_van_de_notulen_van_de_raadsvergadering_van_a_12_ november_2009_b_3_december_2009_17_december_2009/Notulen_17_december_2009/Notulen_17_december_2 009_middagzitting? search $=$ true
} 
planning as well as in terms of their handling? Reconstructions were made to assist in answering these questions.

If we look at the specific features of the visual technologies used to create these reconstructions we see that two features are important. In both cases, registration was very important in collecting evidence. However, they differ in how this registration took place and how it was used. In the Schiphol fire, the evidence was 'recorded' afterwards, while in the Sunset Grooves case the evidence was collected in real time: a television crew was present. At the same time, people present were actually recording what was happening using their digital cameras and mobile telephones. Moreover, if we look at the power of the involved actors that shaped the reconstructions, some differences are noticeable. In the Schiphol case, the reconstruction was dominated by two collaborating parties who had access to the technologies used: the creators of the reconstruction and the Safety Board. As such, they were able to write their own story, determining what visual material would be shown, and in what sequence, and they also had a monopoly over the content of the material shown. Moreover, this monopoly (in terms of resource politics) was also used by the newly established Safety Board to demonstrate its value. In so doing they deliberately left out the heroic actions of the guards. In the Sunset Grooves situation, there was not such a strict monopoly. Admittedly there was a single actor who decided what would be, and in what sequence, shown. However, there was no monopoly in the production of the visual material used. This production was in the hands of many parties (television crews, police officers, and visitors) who had (in terms of resource politics) access to the technologies required to produce and distribute pictures and films. The content of the reconstruction was a result of a process of coproduction or co-creation, although this did not extend to the ordering of the sequence of visual material and scripting for the reconstruction. The script was written by the police although their freedom was limited as the imagery was of an actual chain of events taking place. The makers of the reconstruction were only able to exercise influence by determining what material from what angle would be included, how it was presented, and how specific elements would be stressed in the presentation. Further, given that much of the visual material that was being used was on YouTube, the public could check the material being presented.

Another technological feature that should be stressed was prominent in the Sunset Grooves coproduction process. The combination of visual material, recorded from different angles and positions, enabled the producers of the reconstruction to show how a single incident could be understood from different perspectives. In the Sunset Groove case this was the perspectives of the police officers and of the festival visitors. Hence, the spread of visual technologies among people at an event, and the use of the material so generated, facilitated analytical transparency. However, these different perspectives can also come together, going a step further in the type of transparency achieved. Combining visual material facilitated a more holistic view on what had happened, contributing to a form of integrated transparency.

The two cases show that the transparency achieved is unlikely to be disputed if two conditions are met. First, the trustworthiness of the transparency increases if it is based on real-time information, coming from various public and freely accessible sources that can be checked. In the Sunset Grooves case, visual material was accessible on YouTube. However, the transparency in the Schiphol case could be disputed because the imagery was gathered after the event by a single actor, suggesting manipulation was possible. This suggestion can be explained in terms of the resource monopoly of the organization involved in the production of the images as well as in the technologies used to collect and distribute them. Secondly, the type of story being told and the frames behind the story influence the presented transparency. We see that in our cases the creators of the reconstruction tried to pass their reconstruction off as a forensic story. In the case 
of the Sunset grooves riots we find that the public for a large part accepted this as a forensic story, but in the Schiphol fire case the public perceived the reconstruction as a persuasive story. This demonstrates that even though a creator has actual, factual images, this does not mean that the public will perceive a story as being forensic evidence. The perception of what the story actually is (forensic, persuasive) therefore determines whether transparency is disputed, not the actual quality of forensic material.

This brings us to another set of observations. If we look at the relationship between the production of the reconstruction and the framing of the events in the reconstruction, some interesting similarities and differences can be found in the types of story told.

Firstly we find that in the case of the Sunset Grooves riots case the perception of a forensic story dominated, supporting the dominant frame that the reconstruction makers wanted to put forward. It is a frame in which allegedly the facts are being told, trying to understand in a cool and clinical way what happened: it is the recording and presentation of a sequence of facts that appeals. When comparing this to the Schiphol case we find that the producers wanted to mix two stories. A story of forensic evidence as well as a story to persuade viewers to interpret event in a specific way: i.e. that the government was unable to care for those under their responsibility. This demonstrates that two stories can be told, a persuasive story wrapped into a forensic story, in which motivational framing was very explicit, next to diagnostic and prognostic framing, which would be liked more to a forensic story. We see that the deliberate attempt to insert elements of motivational framing in the Schiphol reconstruction gave rise to a lot of political and public debate due to the political point that the Board was making. However, the reconstruction was not that successful because it was overdramatized. The dramatizing in the Sunset Grooves case is one of a different nature, the real time footage shown was so convincing that the original frame (police's poor organization) faded towards a new frame (threatening situation for the police). This was not done as in the Schiphol case by motivational framing, but more with diagnostic framing because of the live images. Hence, we see that an important design issue in these reconstructions is the extent to which the makers, besides showing the forensic evidence, set out to persuade the audience by excluding or inserting implicit (participants shouting) or explicit (voiceovers, music) persuasive elements in creating an appealing story. This is an important design issue because the composition of a reconstruction influences the accountability discussions that emerge once the reconstruction is shown.

In both our cases, the use of visual material influenced the public and political discussion regarding who was responsible for the fact that several norms were not applied in an appropriate way. In both cases, the diagnostic frames that were presented were adopted in the discussions. Similarly, the motivational frames were also largely adopted, although in Parliament and in the media the deliberate manipulative nature of the Board's motivational framing in the Schiphol case was disputed on the basis of 'going over the top' . In the Sunset Grooves case, the visualized forensic material was so overwhelming and impressive that no additional manipulation was necessary to make a political statement. The fact that these frames were adopted can be explained by the visual power of the reconstructions. The visual technology used offered sophisticated forms of analytical and integrated transparency to help in understanding what had happened. Moreover, the use of these visual reconstructions made it possible to involve a wider public in a more comprehensive and involving way than would otherwise have been possible.

Secondly, given the forensic story that in both cases is been told, it is interesting so, how in both cases the visual material that is being presented 'as photographic truth' is being considered. In both cases the visual material that is used refers to idea of the 'silent witness'. In the detention center case the voice-over literally refers to the material as being 'a silent witness' that 'reveals a hidden truth'. In both cases, the producers and viewers consider the visual reconstruction as being an analogy of what has really been happened, although the way of presenting in the 
detention fire case generates some critique in terms over dramatizing. In the Sunset Groove case the presentation of visual material as well as the quality of the 'photographic truth' is not disputed, nor by the producers nor by the viewers, although the reconstruction was based on a heavy editing. This did not attract attention, because it was not edited as a documentary. Furthermore, in both cases we see that the reconstruction did not stand on its own. It was supported by well-researched reports so that the presented facts could be checked and doublechecked. Hence, the visual reconstructions were consistent with the facts that were obtained from other sources (in terms of provenance). In both cases the investigators want to make use of the visual reconstruction as 'illustrative evidence', while at the same time the imaginative power of this 'illustrative evidence' suppressed the influence of the written report, the logical reasoning which lay behind the report and the other sources of (contextual) information that was taken into account. They got a life of their own.

Furthermore, we see that the visual power of reconstructions can be so convincing that, when it comes to accountability debates, there is hardly any discussion about what actually happened. While one can argue that these visual reconstructions contribute to a process of collective learning, one could also note the lack of a real debate. Moreover, in the Sunset Grooves case, we see that the visual power of the reconstruction was such that a process of reframing took place, changing the original frames that were present immediately after the incidents occurred. In both cases, that story that was presented in the reconstruction dominated the political and public accountability debates.

\section{Conclusions and discussion}

The overall conclusion of this article is that the features of the visual technologies used in reconstructing incidents to frame the causes and effects of incidents, and thereby tell a specific story, strongly influence the nature and form of public and political accountability discussions which emerge following the reconstruction. The two cases clearly show the potential power of these visual reconstructions based on their capacity to re-use recorded visual and forensic evidence in such a way that it supports more advanced forms of analytical and integrated transparency, and can even lead to a process of diagnostic reframing. In both reconstructions the presented visual material was pushed forward as presenting 'a photographic truth' in which a complex reality was being unraveled. However, the transparency achieved is not neutral: it is used to tell a specific story in which the events that have been taken place are framed in a certain way, given the selection and editing process that has taken place when making the reconstruction.

The composition of this story and the diagnostic and motivational framing adopted strongly influence the public and public discussion regarding what has happened, what rules and norms have been violated, and who is responsible. At the same time, the production of these reconstructions is open to both intentional and unplanned forms of manipulation, which undermines the claim of presenting visual material of being an analogy of what has happened, of revealing an hidden 'truth'. Hence, it is important to critically follow the design issues which lay behind the production of the reconstruction, the elements that have been included or left out, and the assumptions which lay behind a reconstruction. Moreover, it is important to know which of the relevant stakeholders had access to two vital resources: the technologies that are used to produce, synthesize, and distribute the relevant visual material; and the visual materials themselves. Accusations of manipulation are easier if specific stakeholders have acquired a monopoly on the visual material as well on the reconstruction's production and distribution. The likelihood of such accusations will diminish if the reconstruction is based on a process of coproduction, and especially if real-time visual material is used, while at the same time the facts that are presented in the reconstruction can be checked and double-checked in terms of 
consistency and provenance. However, this requires the presence of a well-researched report, especially when this report is written by an independent organization. However, we conclude that the images that are presented in the reconstructions suppress the influence of the written report and the logical reasoning that lies behind the report, thereby taken into account all that contextual information which is not made visible by the reconstruction. Although the reconstruction is seen as 'illustrative evidence', in the political and public debate, given the importance that is attached to 'seeing is believing' (Postman, 1993), the reconstruction it is primarily seen as the 'truth', thereby given a voice to the 'silent witness' (Mnookin, 1998).

In putting this conclusion into perspective, and considering the theoretical insights used, we see that the increased use of citizen-produced visual material in reconstructions mirrors the sociocultural changes in our society due the growing use of and reliance on images. The makers of reconstructions can nowadays exploit the fact that our society can be seen as an endless, very often real-time, stream of multiple, sometimes convergent and sometimes divergent, visual events that are not only consumed by citizens but also increasingly produced by them. This convergence and divergence in the multiple images being produced helps to reconstruct incidents from different angles, thereby adding to the ability to create 'the whole picture'. The presentation of this whole truth is based on the presentation of an analogy is presented between the 'facts' of reconstruction and the 'facts' that have really occurred. However, the question is if the presented 'whole picture' in the reconstruction is revealing 'the truth', if the analogy that is presented really represent the facts? We have argued that the diagnostic claim which traditionally is related to the use of photos and videos in order to present 'forensic evidence' and which is now being transferred to using visual reconstructions, should be taken suspiciously. It is the question if the producers of a visual reconstruction or the principles that commissioned a reconstruction are benevolent makers and users, given the fact the that these reconstructions play an important role in blame games; blames games which through the use of visual and digital technologies become mediated blame games. We have shown how socially and politically constructed this 'photographic truth' is. Therefore it is important to acknowledge that power can be exercised when these endless streams of convergent and divergent visual events are ordered in such a way to make a certain sense. That is why it is important to address this issue which lay behind the making of reconstruction: what are the design choices behind the story being told, and how transparent are these choices? The design (selection and editing) choices are especially critical, if the producers and/or the principal responsible actor for the reconstruction have the intention to 'reveal an hidden truth', thereby presenting photographic and video material as forensic evidence. Who's truth is being presented? Hence, an recommendation when analyzing blame games is, to question the visual material that is being used, to understand how relevant actors use visual material to influence the content and course of accountability discussion. Visual reconstructions should therefore not be taken for granted. That is why it is important to de-compose these blamed games and to de-compose the story that is told by the visual reconstruction that are used. There is also another issue related to the emergence of these mediated blame games, which also influence the way in which modern democracies deal with these accountability issues. Typically in today's democracy, citizens experience politics and political issues through the way they are visualized by the media. The interesting thing that these visual reconstructions invite the audience to join a story with which they can identify. One the one hand complex accountability discussions, in terms of what has happened, can be made more understandable in a comprehensive and involved way. It can be experienced, which also stimulates a process of emotional identification with for instance the victims. On the other hand, this can lead to a onesided approach. Although the reconstructions were presented in terms of 'illustrative evidence', the visual power of the reconstruction and the frame that was presented got a life of its own. In doing so, the logical reasoning and the contextual knowledge that was presented in the written research report, was not seriously taken into account. Typical for mediated democracies is that in 
reporting political issues media logic plays an important role (Luhmann, 1990). The media are more likely to report on surprising and unexpected occurrences which complexity is to simple, clear, dramatized and personalized occurrences. This process of selective imaging is enforced by the tendency of the media to refer to themselves, thus causing a repetitive effect, which helps to expand an issue and the frame that is used to discuss the issue. Our research shows that visual reconstructions reinforce this media logic thereby influencing the content of the discussions. The discussions were fueled by the reconstruction and not be the report itself, which can be seen as a threat for a genuine political and public debate. In doing there is a chance that the political agenda is only shaped by accountability issues that can be visualized. Given the tremendous media attention that these visual reconstruction acquire, there is a chance in the fact finding, investigating and reporting process much are attention will be put on the (power of the) visual reconstruction instead of writing a good report.

Furthermore, we see an interesting shift in the making of the reconstructions studied. In the Sunset Grooves case, in contrast to the earlier Schiphol one, citizens were actively invited to take part in the reconstruction. This mirrors another change in our society which has to do with the increased use of social media (web 2.0) that increasingly have a mobile nature by citizens. This is due to the growing penetration of internet-linked telephones which not only can take pictures and videos but also stream them through all kinds of social networks in which experiences are shared. As such, the content of a reconstruction becomes the result of a process of co-creation. This is not, however, an entirely free and open process because there remains an important and powerful gatekeeper: the maker and principals of the reconstruction who decide what pictures are to be used to fit the script they have in mind. Nevertheless, the fact that there is no monopoly on the shooting and sharing of these pictures and films enables citizens to create their own stories over what has happened. In so doing, alternative stories are generated. The possibility to do so, has the potential to create a system of 'checks and balances' in which different frames and stories can be told to understand what has happened, thereby challenging the 'diagnostic truth claim' that is put forward by the official reconstruction.

\section{Literature}

Barnhurst, K., Vari, M. \& Rodríguez, Í. (2004). Mapping Visual Studies in Communication. Journal of Communication 54. pp. 616-644.

Bauman, Z. (2000), Liquid Modernity. Cambridge: Polity Press.

Baumgartner, T., Esslen, M., Janke, L., (2006) From emotional perception to emotion experience: emotions evoked by pictures and classical music. In: International Journal of Psychophisology. Vol 60. pp. 34-43

Bekkers, V. \& V. Homburg (2007). The Myths of E-Government: Looking Beyond the Assumptions of a New and Better Government. In: The Information Society, 23(5), 373-382.

Bennett, L. \& R. Entmann (2001), Mediated politics: an introduction. In: Bennett, L. \& R. Entmann (eds.), Mediated Politics: Communication in the Future of Democracy. Cambridge: Cambridge University Press, pp. 1-29.

Bijker, W., Th. Hughes \& T. Pinch (1987), General introduction, in: Bijker, W., Th. Hughes \& T. Pinch (eds.), The social construction of technological systems. Cambridge Mass: MIT Press, pp. $1-16$.

Bovens, M. (2005), Public Accountability, in: Fergie, B. et al. (eds.), The Oxford Handbook of Public Management, Oxford: OUP, pp. 182-208.

Birkland, T. (1998) Focusing Events, Mobilization, and Agenda Setting. In: Journal of Public Policy 18:1., pp. 53-74.

Castells, M. (1996), The Rise of the Network Society, The Information Age: Economy, Society and Culture. Cambridge: Blackwell.

Crary, J., (1992) Techniques of the Observer. MIT Press 
Day, P. \& R. Klein (1987), Accountabilities: Five Public Services. London: Tavistock

Fishman, J., (2003) News norms and emotions: Pictures of pain and methaphors of distress. In: Gross, L., Stuart, J., Image ethics in the digital age.

Gunning, T.(2004), What's the point of an index? Or, faking photographs, in: NORDICOM Review, vol. 5, no: 1-2, pp. 39-39.

Hajer, M.A.. \& D. Lawes (2006), Ordering through discourse, in: Goodin, R., M. Rein \& M. Moran (eds.), Handbook of Public Policy. Oxford: OUP, pp.250-268.

Hartley, J (1992), The politics of pictures. London/New York: Routledge

Heath, R. and M. Palenchar (2009) Strategic issues management, Sage: Thousand Oaks

Hood, Ch. (2011), The blame game, Princeton/Oxford: Princeton University Press

Kling, R., (1986) The Struggle for Democracy in an Information Society. In: The Information Society. Vol. 4., no. 1/2., pp. 1-7.

Kraemer, K. \& J. King (1986) Computing and public organizations. Public Administration Review, vol. 46, pp. 488-496.

Kraemer, K. \& J. King (2006) Information technology and administrative reform: will egovernment be different? International Journal of E-government Research, 2(1), 1-20.

Lister, M., Dovey, J., Giddings, S., Grant, I., Kelly, K., (2003) New Media: a critical Introduction. Routledge.

Luhmann, N. (1990). Die Wissenschaft der Gesellschaft. Frankfurt am Main: Suhrkamp.

Marcum, J. (2002), Beyond visual culture: the challenge of visual ecology, In: Libraries and the Academy, vol. 2, no. 2, pp. 189-206.

Meijer, A. (2001), Accountability in the Information Age. In: Archival Science, vol.1., nr.4, pp. 361372

Meijer, A. (2007), Holding E-government to account. In: Griffin. D. Et al (ed.), Developments in eGovernment, Amsterdam: IOS Press, pp. 101-111.

Meskin, A. \& J. Cohen (2008), Photographs as Evidence in: Walden, S. (ed.), Photography and Philosophy: Essays on the Pencil of Nature, Oxford: Blackwell pp. 70-91.

Mirzoeff, N. (1999), An introduction to visual culture, London/New York: Routledge

Mitchell, W.(1992), The reconfigured eye. Boston: MIT Press

Mitchell, W. (1994), Picture theory. Chicago: University of Chicago Press.

Mitchell, W. (2005), What do pictures want? Chicago: University of Chicago Press.

Mnookin J. (1998), The image of truth: photographic evidence and the power of analogy, in: Yale Journal of Law \& the Humanities, vol. 10, nr. 1, pp. 1-58

Moody, R., (2010) Mapping Power: Geographical Information Systems, Agenda-setting and Policy Design. Rotterdam.

Orlikowski, W.J., (1992) The Duality of Technology: Rethinking the Concept of Technology in Organizations. Organization Science. Vol. 3. No. 3. pp. 398-427.

Orlikowski, W.J., (2000) Using Technology and Constituting Structures: A Practice Lens for Studying Technology in Organizations. Organization Science. Vol. 11, No. 4. pp. 404-428.

Postman, N. (1993), Technopoly, New York: Vintage

Porter, G. \& M. Kennedy (2012), Photographic truth and evidence, in: Australian Journal of Forensic Sciences, vol. 44, nr 2, pp. 183-192.

Schelder, A, Conceptualizing Accountability, in: Schedler, A., L. Diamond \& M. Plattner (eds.) The self-restraining state, London Boulder: Lynne Rienner, pp. 13-28

Snow, D.A., Rochford, E.B., Worden, S.K., Benford, R.D. (1986), 'Frame Alignment Processes, Micromobilization, and Movement Participation'. American Sociological Review, Vol. 51, No 4, pp. 464-481

Sontag, S. (1977), On Photography, London: Penguin

Stone, D. (1989), Causal stories and the formation of Policy Agenda, Political Science Quarterly, vol. 104, nr. 2, pp. 281-300

Stone, D. (2002), The policy paradox. New York: Norton 
Snellen, I.(1994), De revoluionerende werking van ICT in het openbaar bestuur,in; Zuurmond et al. (1994), Informatisering in bet openbaar bestuur. Den Haag: Lemma, pp. 417-432.

Sturken, M. \& Cartwright, L., (2001), Practices of Looking. Oxford: OUP

Sulitzeanu-Kenan, R. (2006), "If they get it right: An experimental test of the effects of UK public Inquiries" in: Public Administration, vol. 84, nr.3, pp. 623-53.

Sulitzeanu-Kenan, R. \& Ch. Hood (2007), Scything the Grass: Agendasetting Consequences of Appointing Public Inquiries in the UK. In: Policy and Politics, vol. 35, nr. 4, pp. 629-650.

Walgrave, S. \& P. van Aelst (2006), The contingency of the mass media's political agenda setting power: toward a preliminary theory, Journal of Communication, vol. 56, pp. 88-109

Weick, K., (1969) The Social Psychology of Organizing. Reading: Addison-Wesley

Yin, R. (2003), Case study research: design and methods. Newbury Park: Sage 